Childhood socioeconomic status (SES) predicts many important life outcomes, from physical and mental health to academic achievement and cognitive ability. Why is SES so influential? Part of the answer lies in the relationship between SES and the brain. I will present research from my lab and others aimed at characterizing SES differences in brain structure and function. I will then discuss the causes of these associations - by what mechanisms are they linked? - and their consequences - what roles do they play in the health and achievement disparities mentioned earlier? Finally, I will consider whether and how the neuroscience of SES can help shape policies concerning children of low SES.

\section{INFLAMED DEPRESSION}

Edward Bullmore. Department of Psychiatry, University of Cambridge RandD, GlaxSmitKline

\subsection{6/jnnp-2019-BNPA.10}

Edward Bullmore, FRCP, FRCPsych, FMedSci began his medical career as an academic rather than a physician. From 1987 to 1988 , he was a lecturer in medicine at the University of Hong Kong. He then returned to England where he began training in his chosen specialisation as a Senior House Officer in psychiatry at St George's Hospital, London. After a year, he moved hospitals, and was appointed a Registrar in psychiatry at Bethlem Royal Hospital and Maudsley Hospital; both specialist psychiatric hospitals in London. In 1993, Bullmore began his research career. That year, he was appointed a Wellcome Trust Research Training Fellow and served in that role for three years. During that time he studied for a Doctor of Philosophy (PhD) degree at King's College London, which he completed in 1997 with a thesis titled 'Analysis of structural and functional magnetic resonance images of the brain'. In 1996, he was promoted to an Advanced Research Training Fellow for a further three years. His research during this time focused on the mathematical analysis of neurophysiological time series. From 1996 to 1999, he was additionally an honorary Consultant Psychiatrist at Maudsley Hospital, London. In 1999, Bullmore joined the University of Cambridge as Professor of Psychiatry. At college level, he was an elected Fellow of Wolfson College, Cambridge between 2002 and 2010. On 9 October 2014, he was appointed Head of the Department of Psychiatry, University of Cambridge. In 2005, he joined GlaxoSmithKline as Vice-President of Experimental Medicine. From 2005 to 2013, he was also Head of its Clinical Unit based in Addenbrooke's Hospital, Cambridge, Cambridgeshire, which focuses on early clinical drug development projects.

It is beyond doubt that inflammation and depression are associated with each other. Many patients with arthritis, or other inflammatory disorders of the body, have increased risk of depression; many patients with depression have increased blood levels of inflammatory proteins like cytokines. I will discuss how this association has traditionally been interpreted (or discounted) in the Cartesian framework of medical science; and I will highlight new evidence for a direct mechanistic relationship, whereby inflammation of the body or brain can cause depressive behaviours. This raises a number of further questions. First, can known risk factors for depression - like social stress - cause inflammation? Second, what is the current evidence that anti-inflammatory interventions can have antidepressant effects and how could new, more personalized approaches to treatment of 'inflamed depression' (not all depression) be developed in future?.

\section{REFERENCE}

Bullmore ET (2018) 'The Inflamed Mind' Short Books, London.

\section{Day $2-8^{\text {th }}$ March 2019}

\section{Functional neurological disorder and it's boundaries, members' platform, BNPA medal lecture}

\section{THE BLADDER AND THE BRAIN: EXPLORING FUNCTIONAL UROLOGICAL SYMPTOMS}

Ingrid Hoeritzauer. Clinical Research Fellow, University of Edinburgh

10.1136/jnnp-2019-BNPA. 11

Ingrid Hoeritzauer is a neurologist who also has a degree in psychology. She works with the Functional Research Team led by Jon Stone and Alan Carson in Edinburgh and received an ABN/Patrick Berthoud Clinical Research Training Fellowship. Her research interests are observational studies in functional neurological disorders and cauda equina syndrome and her current research focuses on the interface between Uro-Neurology and functional neurological disorders.

This talk will review the current understanding of the bladder-brain axis, and the evidence linking functional disorders, including Functional Neurological Disorder (FND), to bladder symptoms including urinary retention and in the study of patients who present with cauda equina syndrome but have normal scans. Uro-Neurology is the connection between urological symptoms and the neurological system, comprising a complex bladder-brain network involving the brain, spinal cord, sacral nerves and peripheral (pelvic) nerves. Since the time of Charcot there have been hypotheses that urological symptoms, particularly idiopathic urinary retention and overactive bladder symptoms, were part of a functional disorder. However, in the 1980s urethral EMG changes in women with idiopathic urinary retention led to a view that so called 'psychogenic' urinary retention was a primary disorder of the urethral sphincter. Changing views of FND in the last 10 years mean that urological symptoms are once again being investigated as a potential part of functional disorders. Patients presenting with chronic idiopathic urinary retention, diagnosed as Fowler's syndrome, or presenting with acute urinary retention and possible cauda equina syndrome, have been found to have high levels of functional disorder and FND comorbidity ${ }^{1}{ }^{2}$. Additionally, recent papers have suggested central sensitisation as the mechanism of action in patients with idiopathic overactive bladder symptoms. ${ }^{3}$ This newly re-energised field of study requires further exploration, such as investigation of the effect of pathomechanical and medication induced urological symptoms on patients with functional disorders. A practical guide to how to discuss likely functional urological symptoms based on the current level of knowledge will conclude the talk.

\section{REFERENCES}

1. Hoeritzauer I, Stone J, Fowler C, Elneil-Coker S, Carson A, Panicker J. Fowler's syndrome of urinary retention: A retrospective study of co-morbidity. Neurourol Urodyn 2016;35:601-3. 